\title{
Prevalence and correlates of disordered eating in a general population sample: the South East London Community Health (SELCoH) study
}

\author{
F. Solmi · S. L. Hatch $\cdot$ M. Hotopf • \\ J. Treasure $\cdot$ N. Micali
}

Received: 2 October 2013/Accepted: 5 January 2014/Published online: 20 January 2014

(C) The Author(s) 2014. This article is published with open access at Springerlink.com

\begin{abstract}
Purpose Disordered eating has been shown to be more prevalent than full eating disorders diagnoses. However, research on its prevalence, socio-demographic, psychological correlates, and patterns of service use in multiethnic samples is still limited. This paper explores these associations in a South London-based (UK) sample.

Methods The South East London Community Health $(\mathrm{SELCOH})$ study is a general population survey $(N=1,698)$ of individuals aged $16+$. Disordered eating was defined as $\geq 2$ positive answers at the SCOFF questionnaire. Crude and adjusted logistic and multinomial logistic regression models were fit to investigate associations between socio-demographic characteristics, disordered eating, psychiatric comorbidity, and service use.

Results A total of $164(10 \%)$ participants reported disordered eating and the majority were from ethnic minorities. In adjusted models, Asian ethnicity was associated with purging, loss of control eating and preoccupation with food. Individuals with disordered eating had higher odds of
\end{abstract}

Electronic supplementary material The online version of this article (doi:10.1007/s00127-014-0822-3) contains supplementary material, which is available to authorized users.

F. Solmi $(\bowtie) \cdot$ N. Micali

Behavioural and Brain Sciences Unit, Institute of Child Health, University College London, 30 Guilford Street,

WC1N 1EH, London, UK

e-mail: francesca.solmi.10@ucl.ac.uk

S. L. Hatch · M. Hotopf

Psychological Medicine, Institute of Psychiatry, King's College

London, London, UK

J. Treasure

Eating Disorders Department, Institute of Psychiatry, King's

College London, London, UK screening positive for post-traumatic stress disorder and personality disorders and of having anxiety/mood disorders, suicidal ideation/attempts, hazardous levels of drinking, and used drugs in the previous year. Only $36 \%$ of individuals with disordered eating had sought professional help in the previous 12 months mostly through their general practitioner (27.4\%), followed by psychotherapists $(12.8 \%)$ and mental health specialists $(5.5 \%)$.

Conclusion This study found a high prevalence of disordered eating, especially amongst ethnic minorities, and associations with a number of psychiatric conditions. Overall few participants accessed specialist services. These findings suggest that both disordered eating manifestations amongst ethnic minorities and access to care need better investigation.

Keywords Disordered eating · Ethnic minorities . Comorbidity $\cdot$ Mental illness

\section{Introduction}

Eating disorders epidemiology

Eating disorders (ED) are a set of psychiatric conditions traditionally considered of low prevalence in the general population [1-5]. However, increasing evidence suggests that sub-threshold presentations of ED are more prevalent in the population than previously assumed. Whilst lifetime prevalence of anorexia nervosa (AN), bulimia nervosa (BN), and binge eating disorder (BED) has been estimated to range between 0.3 and $0.9 \%, 0.9$ and $1.5 \%$, and $1.9 \%$ and $3.5 \%$ [1], respectively, the lack of uniform sets of diagnostic criteria for their definition has caused prevalence figures for eating disorders not otherwise specified 
(EDNOS) to be generally scant. Nevertheless, a growing body of evidence suggests that EDNOS are more prevalent than $\mathrm{AN}$ and $\mathrm{BN}$ [6-8] and that their incidence has increased [9]. Prevalence of EDNOS has been estimated in the range $2-5 \%[1,7,10,11]$ and they seem to account for the majority of all ED cases diagnosed in outpatients and general population settings, with proportions ranging from 50 to $90 \%$ [6, 8, 11-13]. A recent UK study employing General Practice Research Database (GPRD) data from 2000 to 2009 estimated that the incidence rate of EDNOS in women aged 10-49 has increased from 17.7 per 100,000 in 2000 to 28.4 per 100,000 in 2009 and in men from 3.4 per 100,000 in 2000 to 4.2 per 100,000 in 2009 [9]. A study of 2,520 participants found that $3.9 \%$ (5.9\% women and $1.5 \%$ men) of participants reported any ED behaviours, with higher prevalence among younger and overweight to obese participants [14]. Another study using data from the National Adult Psychiatric Comorbidity Survey 2007 $(N=7,001)$ found $9.1 \%$ of women and $3.4 \%$ of men reporting disordered eating [15].

\section{Comorbidity}

Substantial associations with Axis I (i.e. mood and anxiety disorders, substance abuse) [16] and Axis II (personality disorders) psychiatric comorbidity have been documented in all ED [17]. There is a good evidence that AN, BN, and BED are co-morbid with emotional disorders, both depression [18-24] and anxiety [18], substance use disorders [16, 20-22], and suicidality [16, 20-22]. According to several studies, individuals with EDNOS experience similar co-morbid conditions of those with full-fledged diagnoses [4, 8, 12, 15, 21, 24-26] having increased odds of reporting mood $[8,24,27-30]$ and anxiety disorders [8, 28-30], substance use [8, 21, 24, 30, 31], and suicidality [8, 27]. Individuals with disordered eating are more likely to have higher levels of anxiety and depression [15, 25, 32] compared to healthy individuals. More heterogeneous evidence exists with respect to substance abuse; some studies report evidence of an association with disordered eating [25], and others only find evidence for weaker associations in general population samples than those typically seen in clinical ones [33].

\section{ED in minority groups and help-seeking behaviours}

The majority of research in ED to date has employed samples consisting mainly of women of White European or North American ethnicity. Little is still known about the manifestation and epidemiology of disordered eating among men [34], and, despite a surge in research in the past decade, contradictory results exist when looking at disordered eating in ethnic minorities.
Existing research suggests that ED cognitions and behaviours might have different presentations in males than females [34]. Several studies have found that individuals from Black and other minority groups show fewer body image issues [35, 36] and lower prevalence of AN [2], whilst contrasting results have been found with regards to binge eating, and compensatory behaviours [35]. Nevertheless, most studies have focused on comparisons between Black and White populations, with comparatively less attention paid to Hispanic and Asian groups. A recent meta-analysis uncovered differences in body dissatisfaction between women of White and Black ethnicity, but not between women of White, Asian and Hispanic ethnicity [37]. Hence, more research is needed in multi-ethnic samples to further disentangle these trends.

It is extensively reported in literature that ED patients are reluctant to disclose their symptoms and seek help both at the general medical level and the specialised one. Hudson and colleagues found that only 50-63.2 \% of ED participants had sought help for any emotional problems in their lifetime mostly through general medical services, whereas only about $43 \%$ had sought help for ED specifically. Fewer people (15.6\% with $\mathrm{BN}$ and $28.5 \%$ with BED) sought help through general medical services in the 12 months prior to assessment [4].

Several studies report that members of ethnic minorities suffering from an ED are less likely to present to services to seek help and when they do, they are less likely to receive treatment [38-40]. An American study found that participants Hispanic and Native American ethnicity were less likely than those of White ethnicity to be referred for specialist care evaluation [38]. Similarly, a South Londonbased one found ethnic minority patients to be under-represented in the clinic and less likely to be offered treatment despite being more likely to be diagnosed with an ED [40].

Differences in ED manifestations across different populations (e.g. men, ethnic minorities) coupled with evidence that sub-threshold conditions are often co-morbid with other psychiatric disorders highlight the need for research on disordered eating (i.e. ED behaviours and cognitions) beyond mere diagnoses. This, in turn, could help health professionals identifying 'at risk' individuals, who might otherwise go undetected.

The aims of this paper were: to estimate prevalence and correlates of disordered eating in a general population sample based in South East London, UK; to explore differences across gender, ethnicity and body mass index (BMI) groups; and to explore patterns of service use among individuals with disordered eating. Based on findings of previously mentioned studies, we hypothesised: that disordered eating would be highly prevalent [15]; that disordered eating would be similarly prevalent amongst ethnic minority and White ethnic groups; and that most 
participants would have sought help for a mental health problem through their GP, although fewer from specialist services.

\section{Methods}

Study population

The SELCoH study population was recruited in the two London boroughs of Lambeth and Southwark. The small user postcode address file (PAF) was used as sampling frame to identify households. Households receiving more than 50 items of mail per day were excluded to avoid including business addresses. All eligible individuals aged 16 years and over living within selected and participating households were invited to undertake the survey. More details on recruitment, sampling [41] and representativeness [42] of the SELCoH study population are provided elsewhere. Trained research assistants employing a purposely designed computer-based questionnaire interviewed all SELCoHI participants. Feasibility and reliability of the questionnaire were assessed during an initial pilot study [41]. All participants were interviewed between June 2008 and December 2010 and gave their consent prior to participation to the study.

\section{Measures}

\section{Exposure}

Disordered eating was assessed using the SCOFF questionnaire, a 5-item questionnaire developed by Morgan and colleagues $[43,44]$ as a screening tool for ED. The acronym derives from the initials of the five main words/concepts of each of its questions:

- Do you make yourself Sick because you feel uncomfortably full?

- Do you worry you have lost Control over how much you eat?

- Have you recently lost more than One stone $(6.35 \mathrm{Kg})$ in a 3 month period?

- Do you believe yourself to be Fat even when other say you are too thin?

- Would you say that Food dominates your life?

The SCOFF has been validated in a number of studies and settings, showing good sensitivity and specificity, although low positive predictive value (PPV), especially in general population settings [43, 45-48]. When investigating associations between socio-demographic characteristics (e.g. BMI, ethnicity, age) and disordered eating, both individual questions of the SCOFF and a positive screening status to the questionnaire ( $\geq 2$ positive answers, as suggested by previous literature [43, 44]), were used as outcome measures.

\section{Psychological correlates}

Psychiatric morbidity The revised Clinical Interview Schedule (CIS-R) [49], a 14-item structured questionnaire designed to be used by lay interviewers' in non-clinical settings to assess depressive and anxiety symptoms [50], was used to assess psychiatric comorbidity. Its questions, scored on a $0-4$, or $0-5$ scale (in the case of the depressive ideas scale), cover a number of neurotic symptoms. Scores above a 12-point cut-off indicate suspected presence of a common mental disorder (CMD). An algorithm can be employed to derive primary and secondary diagnoses [49, 51]. To increase power of analyses, we created a threelevel variable from the CIS-R-derived primary diagnoses indicating 'no diagnosis', 'non-specified neurotic disorders' (i.e. all those participants who scored above the 12 point CIS-R cut-off, but did not reach a full diagnosis) and 'mood, anxiety and mixed mood and anxiety disorders' grouped together.

Personality disorder The standardised assessment of personality-abbreviated scale (SAPAS) [52] was employed to screen for symptoms of personality disorders (PD). The SAPAS is an 8-item questionnaire in which each question addresses a personality aspect and is scored $0-1$. Previous studies have identified a cut-off of 3 or 4 as maximising sensitivity and specificity of the instrument [52, 53], although the extent of PPV of the SAPAS in a general population sample has not been validated yet. In this study, a cut-off of 4 was used to define individuals with a PD.

Post-traumatic stress disorder The primary care posttraumatic stress disorder scale (PC-PTSD), a 4-item screening measure designed for use in primary care and other medical settings, was employed to screen for PTSD [54].

Suicidal ideation and/or attempt A variable was derived indicating whether a participant reported having had suicidal ideation or acts. Suicidal ideation was assessed with the question: "have you ever thought of taking your own life, even if you would not really do it?", and suicide attempts with the question: "have you ever made an attempt to take your life, by taking an overdose or in some other way?" Both items had been previously employed by the 2000 and 2007 British National Psychiatric Morbidity surveys $[55,56]$. The rationale for collapsing the two questions was provided by the relatively low prevalence of suicidal attempts [42], the hypothesised low prevalence of disordered eating in the sample and, thus, by the need to 
increase the power of our analyses. Moreover, it is possible to conceptualise suicidal ideation and attempts as elements of a continuum of severity of suicidal behaviours.

Alcohol use Alcohol consumption was investigated with the alcohol use disorders identification test (AUDIT) [57], a screening tool created by the World Health Organization (WHO) to assess excessive drinking. The AUDIT comprises 10 questions scored on a $0-4$ point Likert scale $(0=$ never, $\quad 1=$ less than monthly, $2=$ monthly, $3=$ weekly, $4=$ daily or almost daily). Suggested cut-offs are: $0-7$ 'healthy drinking', 8-15 'hazardous drinking', 16-19 'hazardous and harmful drinking', and $\geq 20$ 'alcohol dependence' [1]. In this study, 'hazardous and harmful drinking' and 'alcohol dependence' were merged to increase power of the analyses.

Any drug use Participants were asked about drug consumption in the previous 12 months. Drugs included in the questionnaire were: Cannabis, Amphetamines, Cocaine, Ecstasy, Acid or LSD, Tranquillisers, Crack, and Heroin. From the individual answers, a summary variable was generated indicating whether the participant had tried at least one drug in the previous 12 months. The rationale for collapsing cannabis use (more frequent) with that of other drugs was that use of any illicit substance could be understood as a marker of risk-taking behaviour.

Smoking Participants' smoking status was coded as a three-level categorical variable indicating 'never smoked', 'ex-smoker', and 'current smoker'.

\section{Help-seeking}

All participants were asked whether they had sought help from a GP or a therapist for a problem with anxiety and depression in the previous year. Those answering positively to this first screening question were asked follow-up questions about whether they had seen a GP, therapist or counsellor, or a mental health specialist. Participants were also asked whether they had received a series of diagnoses. Each diagnosis was asked about individually to account for the possibility of multiple diagnoses.

\section{Socio-demographic characteristics}

Information on participants' anthropometric measures was collected at the time of the interview. BMI was calculated from objective measurements of height and weight and recoded as a 4-level categorical variable indicating whether the participant was underweight (BMI $<18.5$ ), normal weight $(18.5 \leq \mathrm{BMI}<25)$, overweight $(25 \leq \mathrm{BMI}<30)$, or obese (BMI $\geq 30$ ). Age, measured continuously, was subsequently coded into a categorical variable indicating six age groups $(16-24 ; 25-34 ; 35-44 ; 45-54 ; 55-64 ; 65+)$ for ease of interpretation and in line with previous papers [41].

Information was also collected on ethnicity, education level, and marital status. To increase statistical power of analyses, ethnicity was summarised in four categories according to whether the participant was from a White, Black, Asian or any other ethnic background. White ethnic background referred to participants of White British background; Black ethnic background those of both Black African $(N=234,13.8 \%)$ and Black Caribbean $(N=143,8.4 \%)$ ethnicity; and Asian ethnic background those of Indian, Pakistani, Bangladeshi, or Chinese ethnicity. Participants were assigned to the 'any other ethnic background' if they did not identify themselves with any of the categories described above. Education was coded as a 3-level categorical variable indicating whether the participant had no qualifications, completed GCSE (national exams undertaken at age 16) and/or A-levels (national exams undertaken at age 18), or had a higher degree or above. Finally, participants' marital status was recoded as single, married or cohabiting, divorced or separated, or widowed.

\section{Data analyses}

Analyses were conducted accounting for household clustering and weighting for non-response within household. In survey studies, weighting data for non-response are necessary to correct for non-response bias, and generate accurate prevalence estimates and robust standard errors. How inverse probability weights were calculated for the SELCoHI sample is described elsewhere [41].

All analyses were run on individuals with complete outcome and exposure data.

Associations between socio-demographic variables and any disordered eating were described using unweighted frequencies, although weighed prevalence and $95 \%$ CIs were calculated and tested for differences with Pearson's $\chi^{2}$ tests with Rao-Scott correction for categorical data from survey samples [58].

Missing data on socio-demographic variables was assumed to be missing at random (MAR). Missing values for categorical variables were imputed from multinomial logistic models. Distribution of imputed values was visually inspected to ensure comparability with the observed value.

Univariate and multivariate logistic and multinomial logistic regressions were employed to calculate odds ratios (OR) and $95 \%$ confidence intervals (CIs) for the association between disordered eating and behavioural and psychological outcomes, and help-seeking behaviours. In 
Table 1 Socio-demographic characteristics of the SELCoHI sample

\begin{tabular}{|c|c|}
\hline & $N(\%)^{*}$ \\
\hline Total sample & 1,645 \\
\hline \multicolumn{2}{|l|}{ Gender } \\
\hline Male & $714(43.4)$ \\
\hline Female & $931(56.6)$ \\
\hline \multicolumn{2}{|l|}{ Marital status } \\
\hline Single & $665(40.3)$ \\
\hline Married/cohabiting & $754(45.8)$ \\
\hline Divorced/separated/widowed & $226(13.8)$ \\
\hline \multicolumn{2}{|l|}{ Ethnicity $(N=1,643)$} \\
\hline White & $1,024(62.4)$ \\
\hline Black & $362(22)$ \\
\hline Asian & $60(3.7)$ \\
\hline Other & $197(12)$ \\
\hline \multicolumn{2}{|l|}{ Education $(N=1,626)$} \\
\hline No qualification & $208(12.8)$ \\
\hline GCSE/A-level & $738(45.4)$ \\
\hline Degree level or above & $680(41.8)$ \\
\hline \multicolumn{2}{|l|}{$\mathrm{BMI}(N=1,586)$} \\
\hline Underweight & $39(2.5)$ \\
\hline Normal weight & $708(44.7)$ \\
\hline Overweight & $507(32)$ \\
\hline Obese & $332(20.9)$ \\
\hline \multicolumn{2}{|l|}{ Age } \\
\hline $16-24$ & $352(21.4)$ \\
\hline $25-34$ & $396(24.1)$ \\
\hline $35-44$ & $328(19.9)$ \\
\hline $45-54$ & $252(15.3)$ \\
\hline $55-64$ & $152(9.2)$ \\
\hline $65+$ & $165(10.4)$ \\
\hline
\end{tabular}

* Unweighted frequencies, due to missing data might not add up to the full sample

multivariate models, analyses were adjusted for sociodemographic covariates thought a priori to be potential confounders of the association between the exposure and outcomes of interest. Help-seeking outcomes were also adjusted for mood and anxiety disorders, as the question asked if the participants had sought professional help for 'problems with anxiety and depression in the previous year'.

All analyses were performed using Stata12.

\section{Results}

Sample characteristics

A total of 1,698 individuals (age 16-90) took part in SELCoHI. The majority of participants included in the
Table 2 Prevalence estimates for disordered eating across sociodemographic characteristics

\begin{tabular}{|c|c|c|c|c|}
\hline \multirow{2}{*}{$\begin{array}{l}\text { Socio-demographic } \\
\text { characteristics }\end{array}$} & \multirow[t]{2}{*}{$N^{* * *}$} & \multicolumn{2}{|c|}{ Disordered eating } & \multirow[t]{2}{*}{$p$ value $* *$} \\
\hline & & $n$ & $\begin{array}{l}\text { Prevalence* } \\
(95 \% \mathrm{CI})\end{array}$ & \\
\hline Total & 1,645 & 164 & $10.1(8.6-11.8)$ & \\
\hline \multicolumn{5}{|l|}{ Gender } \\
\hline Male & 714 & 42 & $5.9(4.3-7.9)$ & $<0.0001$ \\
\hline Female & 931 & 122 & $12.2(10.2-14.5)$ & \\
\hline \multicolumn{5}{|l|}{ Marital status } \\
\hline Single & 665 & 74 & $11.7(9.3-14.7)$ & 0.13 \\
\hline Married/cohabiting & 754 & 63 & $8.3(6.5-10.7)$ & \\
\hline $\begin{array}{l}\text { Divorced/separated/ } \\
\text { widowed }\end{array}$ & 226 & 27 & $11.2(7.7-16.1)$ & \\
\hline Ethnicity**** & 1,643 & & & \\
\hline White & 1,024 & 80 & $7.9(6.2-9.8)$ & 0.001 \\
\hline Black & 362 & 46 & $12.8(9.6-17)$ & \\
\hline Asian & 60 & 9 & $14.8(7.5-27.2)$ & \\
\hline Other & 197 & 29 & $16.1(11.3-22.4)$ & \\
\hline Education*** & 1,626 & & & \\
\hline No qualification & 208 & 25 & $10.5(7-15.4)$ & 0.02 \\
\hline GCSE/A-level & 738 & 87 & $12.4(10-15.2)$ & \\
\hline Degree level or above & 680 & 50 & $7.4(5.6-9.9)$ & \\
\hline $\begin{array}{l}\text { Body mass index } \\
\text { (BMI)*** }\end{array}$ & 1,586 & & & \\
\hline Underweight & 39 & 4 & $11.4(4.4-26.3)$ & 0.05 \\
\hline Normal weight & 708 & 58 & $8.2(6.3-10.6)$ & \\
\hline Overweight & 507 & 48 & $9.6(7.2-12.7)$ & \\
\hline Obese & 332 & 47 & $13.9(10.4-18.3)$ & \\
\hline \multicolumn{5}{|l|}{ Age } \\
\hline $16-24$ & 352 & 52 & $16.1(12.2-20.9)$ & 0.002 \\
\hline $25-34$ & 396 & 42 & $11.7(8.6-15.6)$ & \\
\hline $35-44$ & 328 & 28 & $9.4(6.6-13.2)$ & \\
\hline $45-54$ & 252 & 24 & $9.9(6.7-14.5)$ & \\
\hline $55-64$ & 152 & 9 & $5.6(2.9-10.7)$ & \\
\hline $65+$ & 165 & 9 & $5.5(2.8-10.4)$ & \\
\hline
\end{tabular}

* Weighted percentages to account for survey design

** Pearson's $c$ test with Rao \& Scott correction for survey data

*** Unweighted frequencies, due to missing data might not add up to the full sample

analyses were women (56.6\%), were educated at least to GCSE/A-levels $(45.4 \%)$ and were from a white background $(62.4 \%)$ (Table 1). However, the sample reflected the ethnic diversity of the studied area and included $22 \%$ of participants from a Black ethnic background (African or Caribbean), $3.7 \%$ from Asian or British Asian background, and $12 \%$ from mixed or other backgrounds. Mean age for the sample was 39.6(SD 16.8 ) with the age group 25-34 years being the most represented $(24.1 \%)$. 
Complete data on all of the outcomes were available for $1,644(96.8 \%)$ participants, who were therefore included in the analyses.

Lower education level $(p<0.0001)$ and older $(55+)$ age $(p<0.0001)$ were associated with missingness. Amongst participants included in the analyses, $95 \%$ had complete data on all covariates; $3 \%$ missed data on BMI, $1 \%$ on education, less than $1 \%$ on ethnicity, and less than $1 \%$ on education and BMI.

\section{Prevalence of disordered eating}

One hundred and sixty-four participants (164, $10 \%)$ reported disordered eating. The SCOFF questions, which were more frequently endorsed, were question 2 related to perceived loss of control $(N=215 ; 13.1 \%)$ and question 3 related to weight loss $(N=206,11.7 \%)$. (Table S1).

\section{Socio-demographic correlates}

As shown in Table 2, more women than men (12.2\% vs. $5.9 \% ; p<0.0001)$ and more participants from the youngest age group $(16.1 \% ; p=0.002)$ reported disordered eating. Disordered eating was most commonly reported by participants of Asian and of mixed or other ethnicity (14.8 and $16.1 \%$ ) followed by those of Black Caribbean and African (12.8\%) and White $(7.9 \%)$ ethnicity $(p=0.001)$. Finally, more participants from the obese BMI group (13.9\%; $p=0.05)$ reported disordered eating.

The distribution of socio-demographic variables across individual SCOFF questions showed that mostly participants of Asian and other ethnic backgrounds endorsed the question on purging behaviours; more men than women and more participants of Black ethnicity endorsed the weight loss question. Participants of Asian ethnicity also mostly endorsed the loss of control eating and preoccupation with food questions. (Table S2).

BMI was associated with loss of control and preoccupation with food. As shown in Table S2, a greater proportion of participants endorsing the loss of control question were from the overweight and obese categories, whereas no differences were shown for preoccupation with food. More underweight participants endorsed the question on purging behaviours.

Strong associations were found between Black, Asian and other ethnicities and disordered eating compared to white ethnicity in the univariate model. However, once adjusting for other socio-demographic characteristics only 'other' ethnic background remained strongly associated with disordered eating (Table 3). When looking at associations between ethnic groups and individual SCOFF answers (Table S3), participants of Asian ethnicity were more likely to report purging (OR 3.7, $95 \%$ CI 1.4-9.8), loss of control (OR 2.2, $95 \%$ CI 1.1-4.2) and preoccupation with food (OR 3.1, $95 \%$ CI 1.5-6.3); and participants of other ethnic backgrounds were more likely to report purging (OR 2.7, $95 \%$ CI 1.4-5.4), body image distortion (OR 2.2, $95 \%$ CI 1.2-3.9), and preoccupation with food (OR 2.4, $95 \%$ CI 1.5-3.9) compared to participants of White ethnicity. No associations were found between Black ethnicity and any of the SCOFF questions.

In univariate models, being obese and in the multivariate models being overweight and obese were associated with disordered eating (Table 3). In multivariate models being overweight was associated with loss of control (OR 1.9, $95 \%$ CI 1.2-2.8), whilst being obese was associated with loss of control (OR 3.2, $95 \%$ CI 2.1-4.9), weight loss (OR 1.6, $95 \%$ CI 1-2.5), and preoccupation with food (OR 1.9, $95 \%$ CI 1.2-3.2) (Table S3).

Finally, as expected, female gender was associated with increased odds of disordered eating. However, females were less likely to endorse weight loss in the previous 3 months (OR 0.6, $95 \%$ CI 0.4-0.8).

Disordered eating and behavioural and psychological outcomes

As shown in Table 4, disordered eating was associated with having greater psychiatric comorbidity, using drugs and drinking hazardous and harmful levels of alcohol in univariate models, but not with smoking. In adjusted analyses, individuals with disordered eating had increased odds of a possible PTSD or PD diagnosis, of having anxiety, mood disorder, or both anxiety and mood disorders, sub-threshold neurotic disorders; and of suicidal ideation/attempts. Disordered eating was also associated with hazardous, and harmful and hazardous levels of drinking, as well as drug use in the previous year (Table 4).

Disordered eating and service use

As shown in Table 5, about a third $(N=59,36 \%)$ of individuals with disordered eating had sought professional help in the year prior to the interview for an anxiety or depression-related problem; the majority saw a GP $(N=45,27.4 \%)$, followed by a therapist $(N=21$, $12.8 \%)$ and mental health specialist $(N=9,5.5 \%)$. About a third of individuals with disordered eating reported that they did not seek help although they thought they needed it $(N=52,31.7 \%)$. Strong associations were found between disordered eating and service use; participants with disordered eating had increased odds of having sought help and of having seen a GP, a mental health therapist or specialist in adjusted models. 
Table 3 Logistic regression analyses of the association between ethnicity, BMI and disordered eating (SCOFF screen positive) (odds ratios, $95 \%$ confidence intervals, $p$ value)

\begin{tabular}{|c|c|c|c|c|c|c|}
\hline & $N$ & $n^{1}$ & $\begin{array}{l}\text { Crude OR } \\
(95 \% \text { CI })\end{array}$ & $p$ value & $\begin{array}{l}\text { Adjusted OR }{ }^{2} \\
(95 \% \mathrm{CI})\end{array}$ & $p$ value \\
\hline Total & 1,645 & 164 & & & & \\
\hline \multicolumn{7}{|l|}{ Ethnicity } \\
\hline White & 1,024 & 80 & 1.0 & - & 1.0 & - \\
\hline Black & 362 & 46 & $1.7(1.2-2.6)$ & 0.008 & $1.2(0.8-1.9)$ & 0.4 \\
\hline Asian & 60 & 9 & $2.0(0.9-4.6)$ & 0.08 & $1.9(0.9-4.6)$ & 0.1 \\
\hline Other & 197 & 29 & $2.3(1.4-3.6)$ & 0.001 & $1.8(1.1-3.0)$ & 0.02 \\
\hline \multicolumn{7}{|l|}{ BMI } \\
\hline Underweight & 39 & 4 & $1.3(0.4-3.8)$ & 0.6 & $1.6(0.5-4.8)$ & 0.3 \\
\hline Normal weight & 708 & 58 & 1.0 & - & 1.0 & - \\
\hline Overweight & 507 & 48 & $1.2(0.8-1.7)$ & 0.4 & $1.5(0.9-2.2)$ & 0.07 \\
\hline Obese & 332 & 47 & $1.7(1.1-2.6)$ & 0.01 & $2.1(1.3-3.4)$ & 0.002 \\
\hline
\end{tabular}

Multiple imputation models

${ }^{1}$ Number of SCOFF positive individuals

2 Adjusted for age, gender, BMI, marital status, ethnicity, and education

Table 4 Logistic regression analyses of behavioural and psychiatric outcomes: SCOFF screen positive vs. SCOFF screen negative (odds ratios, $95 \%$ confidence intervals, $p$ value)

\begin{tabular}{|c|c|c|c|c|c|c|}
\hline Correlates & $N$ & $n^{1}$ & Crude OR (95\% CIs) & $p$ value & Adjusted $\mathrm{OR}^{2}$ (95\% CIs) & $p$ value \\
\hline Total & 1,645 & 164 & & & & \\
\hline \multicolumn{7}{|c|}{ Alcohol use disorders identification test (AUDIT) } \\
\hline No hazard & 1,305 & 124 & 1.0 & - & 1.0 & - \\
\hline Hazardous & 265 & 27 & $1.3(0.8-2.1)$ & 0.3 & $1.7(1.0-3.0)$ & 0.05 \\
\hline Hazardous and harmful & 75 & 13 & $2.4(1.3-4.6)$ & 0.007 & $2.9(1.4-6.1)$ & 0.003 \\
\hline \multicolumn{7}{|l|}{ Smoking status } \\
\hline Non-smoker & 502 & 53 & 1.0 & - & 1.0 & - \\
\hline Current & 704 & 76 & $1.1(0.7-1.6)$ & 0.8 & $1.2(0.7-1.8)$ & 0.5 \\
\hline Ex-smoker & 439 & 35 & $0.7(0.5-1.2)$ & 0.2 & $1.1(0.6-1.8)$ & 0.8 \\
\hline \multicolumn{7}{|l|}{ Primary diagnosis } \\
\hline No diagnosis & 1,212 & 76 & 1.0 & - & 1.0 & - \\
\hline Non-specified neurotic disorder & 108 & 15 & $2.3(1.3-4.2)$ & 0.006 & $2.1(1.1-3.9)$ & 0.02 \\
\hline Anxiety/mood/anxiety + mood disorder & 325 & 73 & $4.1(2.8-5.9)$ & $<0.0001$ & $4.1(2.7-5.9)$ & $<0.0001$ \\
\hline \multicolumn{7}{|l|}{ Any drug use last year } \\
\hline No & 1,286 & 120 & 1.0 & - & 1.0 & - \\
\hline Yes & 359 & 44 & $1.4(1.0-2.1)$ & 0.05 & $1.6(1.1-2.5)$ & 0.03 \\
\hline \multicolumn{7}{|c|}{ Standardised assessment of personality-abbreviated scale (SAPAS) } \\
\hline No & 1,411 & 109 & 1.0 & - & 1.0 & - \\
\hline Yes & 234 & 55 & $3.4(2.4-4.9)$ & $<0.0001$ & $3.2(2.1-4.8)$ & $<0.0001$ \\
\hline \multicolumn{7}{|l|}{ Post-traumatic stress disorder (PTSD) } \\
\hline No & 1,562 & 139 & 1.0 & - & 1.0 & - \\
\hline Yes & 83 & 25 & $4.7(2.8-7.7)$ & $<0.0001$ & $4.5(2.7-7.6)$ & $<0.0001$ \\
\hline \multicolumn{7}{|l|}{ Suicide attempt or ideation } \\
\hline No & 1,290 & 101 & 1.0 & - & 1.0 & - \\
\hline Yes & 355 & 63 & $2.4(1.7-3.5)$ & $<0.0001$ & $2.5(1.7-3.6)$ & $<0.0001$ \\
\hline
\end{tabular}

Multiple imputation models

1 Number of SCOFF positive individuals

2 Adjusted for age, gender, BMI, marital status, ethnicity, and education 
Table 5 Proportion of SCOFF positive and negative participants who sought help for their mental health concerns and odds ratios (OR) and $95 \% \mathrm{CI}$ of the association between disordered eating and help-seeking behaviours

\begin{tabular}{|c|c|c|c|c|c|c|c|c|c|}
\hline \multirow[t]{2}{*}{ Outcome indicator } & \multicolumn{2}{|c|}{ SCOFF negative } & \multicolumn{2}{|c|}{ SCOFF positive } & \multirow[t]{2}{*}{$p$ value } & \multirow{2}{*}{$\begin{array}{l}\text { Crude OR } \\
(95 \% \text { CI })\end{array}$} & \multirow[t]{2}{*}{$p$ value } & \multirow{2}{*}{$\begin{array}{l}\text { Adjusted OR }{ }^{1} \\
(95 \% \mathrm{CI})\end{array}$} & \multirow[t]{2}{*}{$p$ value } \\
\hline & $n$ & $\begin{array}{l}\text { Prevalence } \\
(95 \% \mathrm{CI})\end{array}$ & $n$ & $\begin{array}{l}\text { Prevalence } \\
(95 \% \mathrm{CI})\end{array}$ & & & & & \\
\hline \multicolumn{10}{|l|}{ Sought help } \\
\hline No & 942 & $62.6(59.9-65.3)$ & 53 & $31.8(24.5-39.9)$ & & 1.0 & & 1.0 & \\
\hline No, though I should have & 314 & $21.6(19.4-24)$ & 52 & $31.9(25.1-39.5)$ & $<0.0001$ & $2.9(1.9-4.4)$ & $<0.0001$ & $2.1(1.3-3.3)$ & 0.002 \\
\hline Yes & 225 & $15.7(13.8-17.8)$ & 59 & $36.3(29.1-44.3)$ & & $4.6(3.1-7.1)$ & $<0.0001$ & $3.2(1.9-5.2)$ & $<0.0001$ \\
\hline \multicolumn{10}{|l|}{ Seen a GP } \\
\hline No & 1,319 & $88.6(86.7-90.3)$ & 119 & $72.6(64.9-79.1)$ & $<0.0001$ & 1.0 & & 1.0 & \\
\hline Yes & 162 & $11.4(9.7-13.2)$ & 45 & $27.4(20.9-35.1)$ & & $2.9(1.9-4.4)$ & $<0.0001$ & $2.9(1.9-4.4)$ & $<0.0001$ \\
\hline \multicolumn{10}{|l|}{ Seen a therapist } \\
\hline No & 1,387 & $93.7(92.2-94.9)$ & 143 & $86.9(80.6-91.5)$ & 0.002 & 1.0 & & 1.0 & \\
\hline Yes & 94 & $6.3(5.1-7.8)$ & 21 & $13.1(8.6-19.5)$ & & $2.2(1.3-3.7)$ & 0.003 & $2.5(1.5-4.2)$ & 0.001 \\
\hline \multicolumn{10}{|c|}{ Seen a mental health specialist } \\
\hline No & 1,459 & $98.4(97.6-94.7)$ & 155 & $94.7(90-97.2)$ & 0.001 & 1.0 & & 1.0 & \\
\hline Yes & 22 & $1.6(1-2.4)$ & 9 & $5.3(2.8-9.9)$ & & $3.5(1.6-7.9)$ & 0.003 & $3.2(1.4-7.1)$ & 0.005 \\
\hline \multicolumn{10}{|l|}{ ED diagnosis } \\
\hline N/A & 1,255 & $84.8(82.8-86.6)$ & 105 & $64(56.3-71.1)$ & $<0.0001$ & & & & \\
\hline No & 215 & $14.6(12.9-16.5)$ & 47 & $29.5(22.8-37.3)$ & & & & & \\
\hline Yes & 1 & - & 7 & $4.4(2.1-8.9)$ & & & & & \\
\hline
\end{tabular}

Multiple imputation models

${ }^{1}$ Adjusted for age, gender, BMI, marital status, ethnicity, and education and CMD

\section{Discussion}

This study aimed to determine the prevalence of disordered eating and its correlates in a South East London-based (UK) general population sample. Ten per cent of participants reported disordered eating in the year prior to interview. Disordered eating was more common amongst females and ethnic minorities.

Two recent studies employed the SCOFF questionnaire to estimate disordered eating in the general population [15, 25]. McBride et al. [15] employing data from the UK National Adult Psychiatric Morbidity Survey 2007 found a prevalence of $6.3 \%$. This figure was slightly lower than the one we reported. Differences in the population studied, a UK-wide sample vs. an inner-city sample in our case, are likely to account for this finding, as rates of ED and psychiatric disorders are known to be higher in urban settings [59, 60]. A higher prevalence of disordered eating ( $29.4 \%$ in girls and $14.4 \%$ in boys) was reported by Herpertz-Dahlmann et al. [25] in a sample of 1,895 German adolescents. The difference in prevalence between the latter study and ours could be due to the different age groups of the samples. Some ED are more typical of adolescent age, therefore it is possible that a higher prevalence of disordered eating is detected in younger populations.
In this sample, the most commonly endorsed disordered eating symptoms were loss of control eating, weight loss and preoccupation with food-related thoughts. Although disordered eating was more common amongst women, there were no differences in the prevalence of males or females endorsing each of the SCOFF questions apart from the weight loss question, which was associated with male gender. Recent literature has suggested an increasing awareness among men of body image issues due to societal pressures to adhere to specific models, which might reflect in higher rates of ED behaviours amongst men than those of previous decades [34]. However, the questionnaire was not able to detect further differences between genders, possibly due to the broad nature of the questions asked.

Previous literature had also argued that ethnic minorities might have a decreased risk of developing ED due to lower societal and cultural preferences for thin figures [35, 36]. Older studies reported mixed findings; results have showed lower levels of bulimic symptoms among Black and Asian minorities [61, 62], higher levels of purging behaviours in Black minorities only [61, 63] and higher prevalence of binge-eating in ethnic minorities' women [64]. Our results are in line with some recent studies, showing Asian ethnicity to be associated with ED behaviours. A qualitative study investigating ethnic differences in women's responses of mainstream beauty standards, found that Asian 
women were more likely than Black women to endorse them in a similar fashion to white women, as well as experiencing greater body dissatisfaction [65]. Moreover, a systematic review focusing on children's mental health issues in the UK has highlighted that children and adolescents from an Asian background had the highest levels of ED behaviours amongst all other ethnic minorities in six out of the seven studies included [66]. Finally, a recent South London-based study [40] on a clinical sample of 648 patients assessed for an ED found that a greater proportion of individuals diagnosed with $\mathrm{BN}$ were from ethnic minority groups, of which Asians were the most prevalent. Our findings thus suggest that disordered eating and ED manifestation in ethnic minorities, usually underplayed, need further investigation in multi-ethnic and inner-city settings, where they are more prevalent. It is possible to speculate that environmental and societal factors might play a distinct role in the aetiology of disordered eating in these groups. Stressful life events and discrimination might also influence this association, although this was not investigated in this study. Further research should focus on better understanding these links.

Finally, we found disordered eating associated with the 'other ethnic background' category; however, given the broad range of ethnicities included it is not possible to make specific inferences about associations with some ethnic backgrounds over others.

Individuals of overweight and obese BMI categories (52.9\% of the sample) had increased odds of reporting disordered eating, and loss of control and preoccupation with food, in particular. Previous studies have shown that binge eating is associated with higher BMI [64] and that loss of control eating is associated with anxiety and overweight BMI status [67]. It is therefore possible that disordered eating patterns precede and are associated with higher BMI in these individuals or that weight loss reflects attempts at dieting. However, it is possible that, in some individuals, these episodes of disordered eating behaviours might signal clinically significant conditions. In fact, disordered eating has been shown to be more prevalent in obese groups [68] and that the latter often show high levels of eating restraint [69]. Recent studies have also suggested that increased rates of obesity in society and subsequent attempts to lose weight might act as risk factor for the development of disordered eating, unhealthy weight control practices (i.e. self-induced vomiting, laxatives, fasting) and, possibly, eating disorders [70, 71]. The strong associations found between disordered eating and several psychopathology measures suggest that this hypothesis could be plausible. From this study it is, however, not possible to disentangle these associations and risk mechanisms, although it is interesting to have replicated previous findings suggesting an association between BMI, and disordered eating and loss of control. Future studies should address these hypotheses using longitudinal designs.

We also found an association between disordered eating and comorbidity with possible PD and PTSD; suicidal ideation and attempts; anxiety, mood, or mixed mood and anxiety disorders; and hazardous levels of drinking and drug use. Our results confirm previous findings that ED behaviours, irrespectively of whether they reach full diagnosis, are associated with important comorbidity. This finding is in line with those of previous literature showing that individuals with sub-threshold diagnoses have comparable levels of mood and anxiety disorders [4, 21, 24] and suicidality $[8,25,27,72]$ to those of individuals with fullthreshold ED diagnoses when compared against healthy ones. Individuals exhibiting purging behaviours only have been shown to report these behaviours often at clinical levels [28, 30, 31]. Whilst fewer studies have investigated PD amongst disordered eating participants, evidence seems to suggest an association between the two conditions [28, 73]. Substance use has also been documented in participants with disordered eating and, in particular, amongst those with binge/purge type behaviours [4, 15, 21, 30, 31, 74].

Finally, this study found that although about $30 \%$ of participants with disordered eating reported having seen a GP for problems such as anxiety or depression, only $13 \%$ had seen a mental health therapist and $5 \%$ a mental health specialist. These findings might reflect the UK 'gatekeeper' system where mental health specialists need GP referral. However, it could also reflect the inability of GPs to identify patients with an ED, especially those with bingeeating disorder, who might be otherwise be referred to dieticians, for instance. Finally, it could also imply that the less severe cases might be less likely to attend services or that members of ethnic minorities are less likely to receive an ED diagnosis, as it has been documented in previous literature [38-40]. Since only $7(4.4 \%)$ individuals with disordered eating reported having been diagnosed with an ED, the last two hypotheses seem plausible. Nevertheless, disordered eating was associated with service use.

These results should be interpreted in light of some limitations. ED are highly co-morbid with a number of psychiatric conditions, especially with anxiety and mood disorders. This study, given its cross-sectional nature, was unable to determine temporality, but only to establish the levels of comorbidity associated with disordered eating.

Although $37.6 \%$ of our sample was from a non-White ethnic background it was not possible to investigate in detail differences amongst ethnic minorities, due to low numbers and a high proportion (12\%) of participants from 'other' ethnic background, which was not possible to further identify. Future studies should aim at recruiting bigger samples of participants from ethnic minorities to increase power of analyses and achieve higher precision of results. 
Finally, some of the measures employed to explore comorbidity were screening measures, therefore it was not possible to explore more in detail, the associations highlighted (e.g. which PD was associated with disordered eating). Moreover, the SCOFF questionnaire, a screener measure for eating disorders, was used to define disordered eating. From the SCOFF it is neither possible to derive ED diagnoses nor to estimate reliable sub-scales related to specific ED behaviours, as it is the case for other questionnaires (i.e. EDE-Q). However, the SCOFF has been validated in the general population with good values of sensitivity and specificity $[43,44,46,75]$ and other studies have recently employed it to assess prevalence of disordered eating in large general population samples [15, 25]. Moreover, it captured a group of participants who showed strong associations with co-morbid behaviours which is consistent with evidence showing that that sub-threshold ED presentations might have a similar psychiatric burden to that of full diagnoses.

This study had important strengths. Firstly, it employed a large general population sample representative of the population in the study catchment area, which includes a high proportion of ethnic minorities, ensuring generalizability of the results.

Secondly, these results have significant clinical implications as they suggest the importance of screening for disordered eating in the community, not only to potentially detect individuals with eating disorders, but also, given the comorbidity found with other psychiatric disorders, to identify participants at risk of having or developing further conditions. Findings on lower rates of specialist care attendance amongst disordered eating participants point to the need for better referral systems at GP level, whereas high proportions of participants who reported not having sought help despite feeling the need suggest perhaps the necessity for better community education on mental health to reduce the stigma associated with it. Future studies should employ longitudinal interventions to assess the impact of screening programmes at community (e.g. schools, GP) level on referral rates and mental health morbidity amongst eating disordered participants.

Acknowledgments SLH and MH receive salary support from the National Institute for Health Research (NIHR) Mental Health Biomedical Research Centre at South London and Maudsley NHS Foundation Trust and Institute of Psychiatry, King's College London. This research was supported by the Biomedical Research Nucleus data management and informatics facility at South London and Maudsley NHS Foundation Trust, which is funded by the National Institute for Health Research (NIHR) Mental Health Biomedical Research Centre at South London and Maudsley NHS Foundation Trust and King's College London and a joint infrastructure grant from Guy's and St Thomas' Charity and the Maudsley Charity. This research was also funded by a National Institute of Health Research (NIHR) clinician scientist award to Dr N Micali and by a grant received by the British Academy. These funders had no involvement in study design, data collection, analysis or the decision to submit for publication. The authors have no financial involvement (including employment, fees, share ownership) or affiliation with any organisation whose financial interests may be affected by material in the manuscript, or which might potentially bias it. This publication is the work of the authors and Nadia Micali will serve as guarantors for the contents of this paper.

Conflict of interest The authors declare that they have no conflict of interest.

Ethics declaration Ethics committee approval was sought prior to undertaking the study, which has been performed in accordance with the ethical standards laid down in the 1964 Declaration of Helsinki and its later amendments.

Open Access This article is distributed under the terms of the Creative Commons Attribution License which permits any use, distribution, and reproduction in any medium, provided the original author(s) and the source are credited.

\section{References}

1. Smink FRE, van Hoeken D, Hoek HW (2012) Epidemiology of eating disorders: incidence, prevalence and mortality rates. Curr Psychiatry Rep 14:406-414

2. Hoek HW (2006) Incidence, prevalence and mortality of anorexia nervosa and other eating disorders. Curr Opin Psychiatry 19:389-394

3. Keski-Rahkonen A, Sihvola E, Raevuori A et al (2006) Reliability of self-reported eating disorders: optimizing population screening. Int J Eat Disord 39:754-762

4. Hudson JI, Hiripi E, Pope HG Jr, Kessler RC (2007) The prevalence and correlates of eating disorders in the National Comorbidity Survey Replication. Biol Psychiatry 61:348-358

5. Wade TD, Bergin JL, Tiggemann M et al (2006) Prevalence and long-term course of lifetime eating disorders in an adult Australian twin cohort. Aust N Z J Psychiatry 40:121-128

6. Zimmerman M, Francione-Witt C, Chelminski I et al (2008) Problems applying the DSM-IV eating disorders diagnostic criteria in a general psychiatric outpatient practice. J Clin Psychiatry 69:381-384

7. Machado PPP, Machado BC, Gonçalves S, Hoek HW (2007) The prevalence of eating disorders not otherwise specified. Int J Eat Disord 40:212-217

8. Le Grange D, Swanson SA, Crow SJ, Merikangas KR (2012) Eating disorder not otherwise specified presentation in the US population. Int J Eat Disord 45:711-718

9. Micali N, Hagberg KW, Petersen I, Treasure J (2013) The incidence of eating disorders in the UK in 2000-2009: findings from the General Practice Research Database. BMJ Open. doi:10.1136/ bmjopen-2013-002646

10. Hay PJ, Mond JM, Buttner P, Darby A (2008) Eating disorder behaviors are increasing: findings from two sequential community surveys in South Australia. PLoS One 3:e1541

11. Fairburn CG, Bohn K (2005) Eating disorder NOS (EDNOS): an example of the troublesome "not otherwise specified" (NOS) category in DSM-IV. Behav Res Ther 43:691-701

12. Eddy KT, Celio Doyle A, Hoste RR et al (2008) Eating disorder not otherwise specified in adolescents. J Am Acad Child Adolesc Psychiatry 47:156-164 
13. Turner H, Bryant-Waugh R (2004) Eating disorder not otherwise specified (EDNOS): profiles of clients presenting at a community eating disorder service. Eur Eat Disord Rev 12:18-26

14. Hilbert A, de Zwaan M, Braehler E (2012) How frequent are eating disturbances in the population? Norms of the eating disorder examination-questionnaire. PLoS One. doi:0.1371/journal. pone. 0029125

15. McBride O, McManus S, Thompson J et al (2012) Profiling disordered eating patterns and body mass index (BMI) in the english general population. Soc Psychiatry Psychiatr Epidemiol 48:783-793

16. Godart NT, Perdereau F, Rein Z et al (2007) Comorbidity studies of eating disorders and mood disorders. Critical review of the literature. J Affect Disord 97:37-49

17. Cassin SE, von Ranson KM (2005) Personality and eating disorders: a decade in review. Clin Psychol Rev 25:895-916

18. O’Brien KM, Vincent NK (2003) Psychiatric comorbidity in anorexia and bulimia nervosa: nature, prevalence, and causal relationships. Clin Psychol Rev 23:57-74

19. Karatzias T, Chouliara Z, Power K et al (2010) General psychopathology in anorexia nervosa: the role of psychosocial factors. Clin Psychol Psychother 17:519-527

20. Kessler RC, Berglund PA, Chiu WT et al (2013) The prevalence and correlates of binge eating disorder in the World Health Organization World Mental Health Surveys. Biol Psychiatry 73:904-914

21. Swanson SA, Crow SJ, Le Grange D et al (2011) Prevalence and correlates of eating disorders in adolescents. Results from the national comorbidity survey replication adolescent supplement. Arch Gen Psychiatry 68:714-723

22. Grucza RA, Przybeck TR, Cloninger CR (2007) Prevalence and correlates of binge eating disorder in a community sample. Compr Psychiatry 48:124-131

23. Sonneville KR, Horton NJ, Micali N et al (2013) Longitudinal associations between binge eating and overeating and adverse outcomes among adolescents and young adults: does loss of control matter? JAMA Pediatr 167:149-155

24. Field AE, Sonneville KR, Micali N et al (2012) Prospective association of common eating disorders and adverse outcomes. Pediatrics 130:e289-e295

25. Herpertz-Dahlmann B, Wille N, Hölling H et al (2008) Disordered eating behaviour and attitudes, associated psychopathology and health-related quality of life: results of the BELLA study. Eur Child Adolesc Psychiatry 17(Suppl 1):82-91

26. Lavik NJ, Clausen SE, Pedersen W (1991) Eating behaviour, drug use, psychopathology and parental bonding in adolescents in Norway. Acta Psychiatr Scand 84:387-390

27. Wade TD (2007) A retrospective comparison of purging type disorders: eating disorder not otherwise specified and bulimia nervosa. Int J Eat Disord 40:1-6

28. Keel PK, Haedt A, Edler C (2005) Purging disorder: an ominous variant of bulimia nervosa? Int J Eat Disord 38:191-199

29. Keel PK, Wolfe B, Gravener J, Jimerson D (2008) Co-morbidity and disorder-related distress and impairment in purging disorder. Psychol Med 38:1435-1442

30. Solmi F, Sonneville KR, Easter A, et al. Purging behaviours at age 16: prevalence in three community-based international cohorts (under review)

31. Abebe DS, Lien L, Torgersen L, von Soest T (2012) Binge eating, purging and non-purging compensatory behaviours decrease from adolescence to adulthood: A population-based, longitudinal study. BMC Public Health. doi:10.1186/1471-2458-12-32

32. Zaider TI, Johnson JG, Cockell SJ (2000) Psychiatric comorbidity associated with eating disorder symptomatology among adolescents in the community. Int J Eat Disord 28:58-67
33. Von Ranson KM, Iacono WG, McGue M (2004) Disordered eating and substance use in an epidemiological sample: I. Associations within individuals. Int J Eat Disord 31:389-403

34. Strother E, Lemberg R, Stanford SC, Turberville D (2012) Eating disorders in men: underdiagnosed, undertreated, and misunderstood. Eat Disord 20:346-355

35. Shaw H, Ramirez L, Trost A et al (2003) Body image and eating disturbances across ethnic groups: more similarities than differences. Psychol Addict Behav 18:12-18

36. Kronenfeld LW, Reba-Harrelson L, Von Holle A et al (2010) Ethnic and racial differences in body size perception and satisfaction. Body Image 7:131-136

37. Grabe S, Hyde JS (2006) Ethnicity and body dissatisfaction among women in the United States: a meta-analysis. Psychol Bull 132:622-640

38. Becker AE, Franko DL, Speck A, Herzog DB (2003) Ethnicity and differential access to care for eating disorder symptoms. Int $\mathbf{J}$ Eat Disord 33:205-212

39. Cachelin FM, Striegel-Moore RH (2006) Help seeking and barriers to treatment in a community sample of Mexican American and European American women with eating disorders. Int $\mathbf{J}$ Eat Disord 39:154-161

40. Waller G, Schmidt U, Treasure J et al (2009) Ethnic origins of patients attending specialist eating disorders services in a multiethnic urban catchment area in the United Kingdom. Int J Eat Disord 42:459-463

41. Hatch SL, Frissa S, Verdecchia M et al (2011) Identifying sociodemographic and socioeconomic determinants of health inequalities in a diverse London community: the South East London Community Health (SELCoH) study. BMC Public Health. doi:10.1186/1471-2458-11-861

42. Aschan L, Goodwin L, Cross S et al (2013) Suicidal behaviours in South East London: prevalence, risk factors and the role of socio-economic status. J Affect Disord 150:441-449

43. Morgan JF, Reid F, Lacey JH (1999) The SCOFF questionnaire: assessment of a new screening tool for eating disorders. BMJ 319:1467-1468

44. Morgan JF, Reid F, Lacey JH (2000) The SCOFF questionnaire: a new screening tool for eating disorders. West J Med 172:164-165

45. Mond JM, Myers TC, Crosby RD et al (2008) Screening for eating disorders in primary care: EDE-Q versus SCOFF. Behav Res Ther 46:612-622

46. Luck AJ (2002) The SCOFF questionnaire and clinical interview for eating disorders in general practice: comparative study. BMJ 325:755-756

47. Cotton M-A, Ball C, Robinson P (2003) Four simple questions can help screen for eating disorders. J Gen Intern Med 18:53-56

48. Parker SC, Lyons J, Bonner J (2005) Eating disorders in graduate students: exploring the SCOFF questionnaire as a simple screening tool. J Am Coll Health 54:103-107

49. Lewis G, Pelosi AJ, Araya R, Dunn G (1992) Measuring psychiatric disorder in the community: a standardized assessment for use by lay interviewers. Psychol Med 22:465-486

50. Botega NJ, Pereira WA, Bio MR et al (1995) Psychiatric morbidity among medical in-patients: a standardized assessment (GHQ-12 and CIS-R) using "lay" interviewers in a Brazilian hospital. Soc Psychiatry Psychiatr Epidemiol 30:127-131

51. Patton GC (1998) Depression, Anxiety, and Smoking Initiation: A Prospective Study Over 3 Years. Am. J. Public Heal 88:1518

52. Moran P (2003) Standardised assessment of personality-abbreviated scale (SAPAS): preliminary validation of a brief screen for personality disorder. Br J Psychiatry 183:228-232

53. Pluck G, Sirdifield C, Brooker C, Moran P (2012) Screening for personality disorder in probationers: validation of the standardised assessment of personality-abbreviated scale (SAPAS). Personal Ment Health 6:61-68 
54. Frissa S, Hatch SL, Gazard B et al (2013) Trauma and current symptoms of PTSD in a South East London community. Soc Psychiatry Psychiatr Epidemiol 48:1199-1209

55. Meltzer H, Lader D, Corbin T et al (2002) Non-fatal suicidal behaviour among adults aged 16 to 74 in Great Britain. The Stationary Office, London

56. Nicholson S, Jenkins R, Meltzer H (2009) Suicidal thoughts, suicide attempts and self-harm. In: McManus S, Meltzer $\mathrm{H}$, Brugha $\mathrm{T}$ et al (eds) Adult Psychiatric Morbidity in England, 2007. Results of a household survey. National Centre for Social Research, London, pp 71-87

57. Babor TF, Higgins-Biddle JC, Saunders JB, Monteiro MG (2001) AUDIT - the alcohol use disorders identification test: guidelines for use in primary care, 2nd edn. World Health Organization, Geneva

58. Rao JNK, Scott AJ (1987) On simple adjustments to chi square tests with sample survey data. Ann Stat 15:385-397

59. Favaro A (2003) The spectrum of eating disorders in young women: a prevalence study in a general population sample. Psychosom Med 65:701-708

60. Hoek HW, Bartelds AI, Bosveld JJ et al (1995) Impact of urbanization on detection rates of eating disorders. Am J Psychiatry $152: 1272-1278$

61. Field AE, Camargo CA, Taylor CB et al (1999) Relation of peer and media influences to the development of purging behaviors among preadolescent and adolescent girls. Arch Pediatr Adolesc Med 153:1184-1189

62. Nevo S (1985) Bulimic symptoms: prevalence and ethnic differences among college women. Int J Eat Disord 4:151-168

63. Striegel-Moore RH, Smolak L (2000) The influence of ethnicity on eating disorders in women. In: Eisler RM, Herse M (eds) Handbook of gender, cultural health. Taylor \& Francis, UK, pp 219-244

64. Marcus MD, Bromberger JT, Wei H-L et al (2007) Prevalence and selected correlates of eating disorder symptoms among a multiethnic community sample of midlife women. Ann Behav Med 33:269-277
65. Chin Evans P, McConnell AR (2003) Do racial minorities respond in the same way to mainstream beauty standards? Social comparison processes in asian, black, and white women. Self Identity 2:153-167

66. Goodman A, Patel V, Leon DA (2008) Child mental health differences amongst ethnic groups in Britain: a systematic review. BMC Public Health. doi:10.1186/1471-2458-8-258

67. Goossens L, Braet C, Van Vlierberghe L, Mels S (2009) Loss of control over eating in overweight youngsters: the role of anxiety, depression and emotional eating. Eur Eat Disord Rev 17:68-78

68. De Zwaan M (2001) Binge eating disorder and obesity. Int J Obes Relat Metab Disord 25(Suppl 1):S51-S55

69. Roehrig M, Masheb RM, White MA, Grilo CM (2009) Dieting frequency in obese patients with binge eating disorder: behavioral and metabolic correlates. Obesity 17:689-697. doi:10.1038/oby. 2008.600

70. Neumark-Sztainer D (2005) Can we simultaneously work toward the prevention of obesity and eating disorders in children and adolescents? Int J Eat Disord 38:220-227. doi:10.1002/eat.20181

71. Haines J, Neumark-Sztainer D (2006) Prevention of obesity and eating disorders: a consideration of shared risk factors. Health Educ Res 21:770-782

72. Crow SJ, Peterson C, Swanson SA et al (2009) Increased mortality in bulimia nervosa and other eating disorders. Am J Psychiatry $166: 1342-1346$

73. Marino MF, Zanarini MC (2001) Relationship between EDNOS and its subtypes and borderline personality disorder. Int $\mathrm{J}$ Eat Disord 29:349-353

74. Krug I, Treasure J, Anderluh M et al (2008) Present and lifetime comorbidity of tobacco, alcohol and drug use in eating disorders: a European multicenter study. Drug Alcohol Depend 97:169-179

75. Garcia-Campayo J, Sanz-Carrillo C, Ibañez JA et al (2005) Validation of the Spanish version of the SCOFF questionnaire for the screening of eating disorders in primary care. J Psychosom Res 59:51-55 